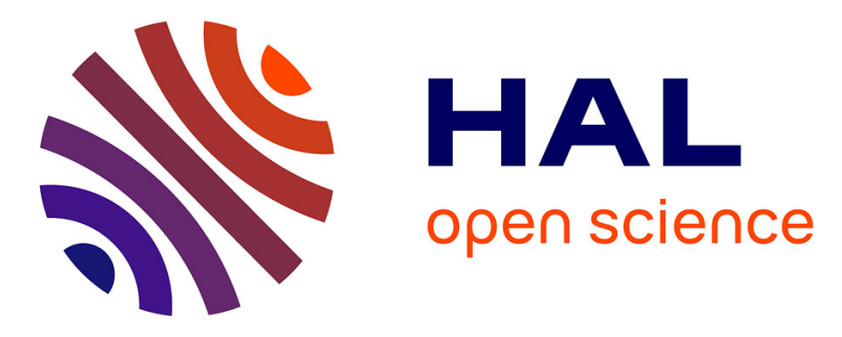

\title{
A mathematical model for tailoring antimicrobial packaging material containing encapsulated volatile compounds
}

\author{
Mia Kurek, Yannick Laridon, Elena Torrieri, Valérie Guillard, Astrid Pant, \\ Cornelia Stramm, Nathalie Gontard, Carole Guillaume
}

\section{To cite this version:}

Mia Kurek, Yannick Laridon, Elena Torrieri, Valérie Guillard, Astrid Pant, et al.. A mathematical model for tailoring antimicrobial packaging material containing encapsulated volatile compounds. Innovative Food Science \& Emerging Technologies / Innovative Food Science and Emerging Technologies , 2017, 42, pp.64-72. 10.1016/j.ifset.2017.05.014 . hal-01606936

\section{HAL Id: hal-01606936 https://hal.science/hal-01606936}

Submitted on 25 May 2020

HAL is a multi-disciplinary open access archive for the deposit and dissemination of scientific research documents, whether they are published or not. The documents may come from teaching and research institutions in France or abroad, or from public or private research centers.
L'archive ouverte pluridisciplinaire HAL, est destinée au dépôt et à la diffusion de documents scientifiques de niveau recherche, publiés ou non, émanant des établissements d'enseignement et de recherche français ou étrangers, des laboratoires publics ou privés. 


\section{Accepted Manuscript}

A mathematical model for tailoring antimicrobial packaging material containing encapsulated volatile compounds

Mia Kurek, Yannick Laridon, Elena Torrieri, Valérie Guillard, Astrid Pant, Cornelia Stramm, Nathalie Gontard, Carole Guillaume

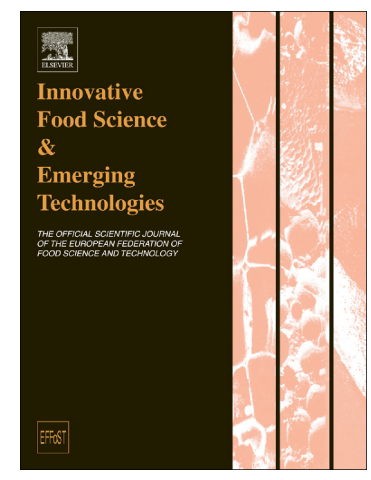

PII:

S1466-8564(17)30601-X

DOI: doi: 10.1016/j.ifset.2017.05.014

Reference: INNFOO 1768

To appear in: Innovative Food Science and Emerging Technologies

Received date: 29 March 2016

Revised date: 19 April 2017

Accepted date: 31 May 2017

Please cite this article as: Mia Kurek, Yannick Laridon, Elena Torrieri, Valérie Guillard, Astrid Pant, Cornelia Stramm, Nathalie Gontard, Carole Guillaume, A mathematical model for tailoring antimicrobial packaging material containing encapsulated volatile compounds, Innovative Food Science and Emerging Technologies (2017), doi: 10.1016/ j.ifset.2017.05.014

This is a PDF file of an unedited manuscript that has been accepted for publication. As a service to our customers we are providing this early version of the manuscript. The manuscript will undergo copyediting, typesetting, and review of the resulting proof before it is published in its final form. Please note that during the production process errors may be discovered which could affect the content, and all legal disclaimers that apply to the journal pertain. 


\title{
A mathematical model for tailoring antimicrobial packaging material containing encapsulated volatile compounds
}

Kurek, Miaa; Laridon, Yannickª Torrieri Elenab; Guillard, Valérie*a; Pant, Astridc; Stramm, Corneliac; Gontard, Nathalie ; Guillaume, Carole

a Joint Research Unit Agropolymers Engineering and Emerging Technologies, UMR 1208 INRA/SupAgroM/UMII/CIRAD, 2 Place Pierre Viala, 34060 Montpellier, France

b Food Science and Agricultural Department, University of Naples Federico II, Via Università 100, 80055 Portici, NA, Italy

c Fraunhofer IVV Institute for Process Engineering and Packaging, Giggenhauser Straße 35, Freising, Germany

*corresponding author, guillard@univ-montp2.fr

\section{Keywords:}

active packaging; diffusion-reaction; AITC; experimental validation, PLA

\begin{abstract}
:
A mathematical model describing the water content-dependent release of an antimicrobial agent (allyl isothiocyanate (AITC)) from a bio-based film to the packaging headspace was implemented. The system was characterised experimentally by assessing release kinetics and diffusivities. The model was validated by comparing simulations to experimental data. In spite of the high complexity of the system coupling moisture and antimicrobial diffusion within the packaging material and then release into headspace, the presented model provides a good enough reproduction of experimental conditions. A sensitivity study conducted on the model showed that the release kinetics of the antimicrobial agent were the most influential parameters, and that the diffusivity of moisture and AITC within the film have negligible impact. The model was then used to demonstrate the efficiency of such packaging for shelf-life optimization as it successfully inhibited the growth of bacteria. This work provides a framework that can be used for decision support systems.
\end{abstract}




\section{Nomenclature}

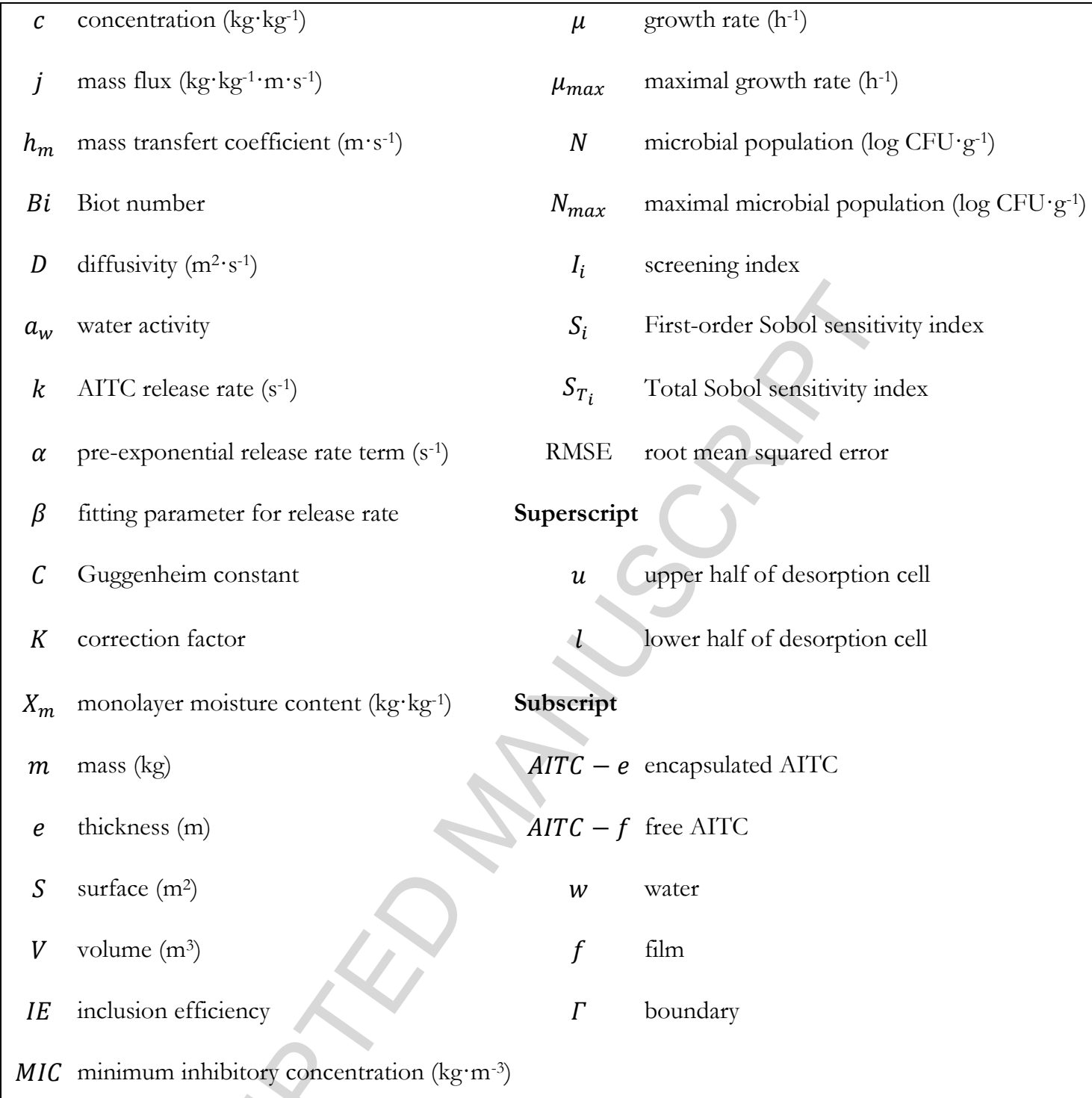




\section{Introduction}

Active packaging technologies involve the design and dimensioning of food packaging system for extending food shelf life, while maintaining its quality and safety. Active packaging deliberately incorporates active components intended to release or to absorb substances into, onto or from the packaged food or the environment surrounding the food (Angellier-Coussy et al., 2013; Ozdemir and Floros, 2004). They act on different reactions of degradation of food or as a vector of compounds of interest. Antimicrobial packaging acts by direct contact or by emitting some volatile antimicrobial compounds into the headspace to limit microbial growth on the surface of the food. In this last case, the shelf life of the packed food product depends mainly on the composition of volatile compounds in the headspace, which in turn determines the growth rate of microorganisms. This headspace composition is a function of the diffusion of the active agent into the polymer matrix and its release rate from the packaging toward the headspace and of the environmental conditions (e.g. temperature, relative humidity) that could strongly impact the aforementioned transfer rates (Mascheroni et al., 2011). In this context, the dimensioning of the antimicrobial packaging material is meant to adjust the quantity of active agent to add in the material during processing, knowing among others, its diffusivity into the matrix, its release conditions and its expected effect on the targeted degradation reaction (e.g. microbial growth). Mathematical models of mass transfer are very helpful to achieve this task and constitute a real decision support tool for researchers and packaging and food manufacturers.

During the last few years, the research on antimicrobial food packaging material has significantly increased as an alternative method to control unwanted microbial growth in foods. The latest progresses in that field have focused on material development with the design of polymeric matrices with tailored mass transfer properties (diffusivity) to control the release (Joo et al., 2012; Lagaron et al., 2007; Mascheroni et al., 2010a, 2011; Raouche et al., 2011) and on the development of tools based on complex diffusion-reaction systems to predict the antimicrobial release. These approaches aimed at a better design of the antimicrobial packaging by choosing optimal transport parameters for a given situation (Guillard et al., 2009; Mascheroni et al., 2010b). Among volatile antimicrobial compounds, allyl isothiocyanate (AITC, a major flavour component of mustard essential oil) has been shown to have a strong antimicrobial activity in its vapour form for very weak added concentrations, compared to others antimicrobial volatile agents (Delaquis and Sholberg, 1997; Raouche et al., 2011). In order to reduce its volatility and its thermal degradation when incorporating it into polymer matrices, usually shaped by using thermo-mechanical processes such as cast-extrusion, AITC can be encapsulated in $\alpha$ - or $\beta$-cyclodextrins, prior incorporation in the matrix (Ohta et al., 2004). 
$\beta$-cyclodextrin $(\beta-C D)$ is a cyclic oligosaccharide consisting of seven glucopyranose units linked by alpha-(1-4) bonds (Del Valle, 2004). $\beta$-CD is most used for its ability to form solid inclusion complexes (host-guest complexes) by molecular complexation with a very wide range of compounds: due to its lipophilic nature, the cavity of $\beta$-CD constitutes an appropriate host site for apolar molecules to form inclusion complexes (Fang et al., 2013). If the complexation is made in aqueous solution, water molecules in the cavity of $\beta-\mathrm{CD}$ are replaced by the more hydrophobic molecules (here AITC) in the solution. This new apolarapolar association is more stable with a lower energy level (Del Valle, 2004). Once the complex is formed, dried and then rehydrated, the addition of water may cause the breakdown of the system and the release of the encapsulated hydrophobic molecules.

Among possible applications, complexes of $\beta$-CD with allyl isothiocyanate (AITC) have been evaluated as a slow-release additive in polylactide-co-polycaprolactone (PLA-PCL) biopolymer film packaging. Such encapsulation has been shown to be suitable for long shelf life storage packaging of cheeses (Plackett et al., 2007, 2006). The release of AITC from $\beta$ $\mathrm{CD}$ is known to depend on relative humidity: the higher the relative humidity, the faster and the higher the release. Ponce Cevallos and coworkers (2010) showed that cinnamon and thymol $\beta$-CD complexes remained stable up to $75 \%$ RH during long storage times (60 days at $\left.25^{\circ} \mathrm{C}\right)$. The guests released from the $\beta-\mathrm{CD}$ complexes were detectable in the region of the water adsorption isotherm at which a sharp increase of water content occurred $(84 \% \mathrm{RH})$. The authors emphasized that the release of guest molecules was thus governed by the shape of the water sorption isotherm. Li et al. (2007) proposed and validated a release model and showed that depending on the relative humidity $(\mathrm{RH})$ level and on limiting diffusive effects, the release could range from $20 \%(50 \% \mathrm{RH}$ and diffusion-limited system) to $100 \%$ (nonlimiting systems or $98 \%$ RH for diffusion-limited systems) of encapsulated AITC. In order to improve knowledge of AITC release mechanisms from polymeric films, it appears thus fundamental to deepen the study of water- $\beta$-CD-AITC interactions and especially the impact of water transfer in the film on the diffusion and release rate of AITC. Mathematical modelling of the coupled mass transfer and reaction phenomena prevailing in such a system is crucial to fix its complexity. Release of compounds from $\beta-C D$ was extensively studied in simplified experimental conditions such as aqueous solutions (for instance Ohta et al. 2000; Reineccius et al., 2003), but as far as we know few of these approaches were then integrated in a full packaging concept (including polymer matrix containing encapsulated active compound and headspace).

In the context of active packaging research, models can provide a better understanding of the interplay between the mechanisms involved. However, the predictive ability of such models depends highly on an adequate experimental determination of input parameters. Huang et al. (2013) proposed a general model for active packaging, but it was not designed 
for encapsulated compounds and lacked experimental validation. Cerisuelo et al. $(2012,2013)$ have developed a mathematical model to describe the moisture-dependent release of carvacrol in a hydrophilic EVOH coating on PP film for packaging salmon fillets. Their modelling approach helped the optimisation of the package design and the identification of the best environmental conditions that would lead to the achievement of maximum packaging efficiency. In this respect, the use of decision support tools based on mathematical models coupling mass transfer occurring in the packaging (such as diffusion and release of additives, scavenging of certain species, etc.) and reaction in the food product (such as microbial growth, oxidation, respiration, etc.) is helpful to simplify the package design steps by allowing predicting in advance the packaging mass transfer properties or composition (e.g. quantity of active compound to add in the material) for maintaining the quality of the packed food. Specific modelling tools have already been developed for modified atmosphere packaging systems coupling gas transfer and respiration for fresh fruits and vegetables (Cagnon et al., 2013; Mahajan et al., 2007; Xanthopoulos et al., 2012) or gas transfer and predictive microbiology (Chaix et al., 2015; Simpson and Carevic, 2004). Such tools still remain to be developed in the field of antimicrobial packaging films.

The objective of this work was to develop a mathematical model to describe the water content-dependent release of AITC encapsulated in $\beta$-CD from a polymeric matrix. To do so, the following steps were undertaken:

- Model the release of AITC from $\beta-C D$ as a function of relative humidity;

- Model the coupling of water mass transfer and AITC release kinetics;

- Experimentally validate the model;

- Explore the use of this mechanistic model as a tool for designing efficient antimicrobial packaging system.

The model was further characterised by means of a sensitivity study.

\section{Materials and methods}

\subsection{Chemicals}

Allyl isothiocyanate (AITC) was purchased from Sigma Aldrich (St Louis, USA) with the highest purity available (97\%). PEG 5000, reagent grade, was purchased from Fluka (Sigma Aldrich, St Louis, USA). $\beta$-CD powder was purchased from Roquette (Lestrem, France). For film production, PLA 2003D (NatureWorks) pellets were used. Prior to processing, the PLA was dried at $60^{\circ} \mathrm{C}$ for $24 \mathrm{~h}$. 


\subsection{Preparation of AITC inclusion complexes with $\beta$-CD}

$\beta-C D$ was mixed with deionized water at weight ratio 3:1 in a kneader for $10 \mathrm{~min}$ at $80 \mathrm{rpm}$. AITC was added with a molar ratio $\beta$-CD/AITC of 1:1 and the paste was further mixed for $20 \mathrm{~min}$ at $80 \mathrm{rpm}$. The mixture was then freeze-dried for 4 days. The dried granules were ground in a kitchen mixer. The resultant dried powder was put into the turbo separator in order to separate fine particles ( $<20$ microns) from coarse particles. The finer particles were stored at $5{ }^{\circ} \mathrm{C}$ in dry conditions using silica gel.

The inclusion efficiency of AITC in $\beta$-CD complex was evaluated to be about $66 \%$ using Eq. 1 (from Raouche et al., 2011):

$$
I E=\text { Inclusion efficiency }=100 \frac{\text { Total AITC-Surface AITC }}{\text { Theoretical AITC }}
$$

where total AITC is the quantity of AITC in in $\beta$-CD complex, surface AITC is the quantity of AITC on the surface of $\beta$-CD complex and theoretical AITC is the theoretical calculation of maximum AITC quantity that can be encapsulated in $\beta$-CD. The theoretical AITC concentration was $0.087 \mathrm{~kg}$ of AITC per $\mathrm{kg}$ of $\beta-\mathrm{CD}$, that is to say the ratio between the molar mass of AITC and $\beta$-CD.

\section{$2.3 \quad$ Film processing}

In a first step PLA was melt-blended with $5 \%(\mathrm{w} / \mathrm{w})$ of $\beta$-CD-AITC in a lab scale compounder (Dr. Collin GmbH, Germany) with a L/D ratio of 24 and a $3 \mathrm{~mm}$ rod die. Temperatures of 150/160/175/175/190 (zones 1-5) and a screw speed of $40 \mathrm{~min}^{-1}$ were applied. The melt pressure was 75 bar. The resulting melt strain (diameter ca. $2 \mathrm{~mm}$ ) was cooled down with dry ice and cut into pellets. The pellets were then used for cast film extrusion on a lab scale extrusion line (Dr. Collin GmbH, Germany). The extruder has a $\mathrm{L} / \mathrm{D}$ ratio of 25; a slot die of $30 \mathrm{~mm}$ diameter was used. Processing temperatures were 160/180/180/180/180 (zones 1-4 /slot die), the screw speed $37 \mathrm{~min}^{-1}$ and the melt pressure 79 bar. Film thickness was adjusted to $50 \mu \mathrm{m}$. The films were stored on reels under dry conditions $\left(100 \%\right.$ nitrogen) at $23^{\circ} \mathrm{C}$ until further examination.

\subsection{Determination of AITC release from $\beta$-CD}

Samples of $\beta$-CD-AITC were analysed by dynamic method in the experimental apparatus schematically represented in Figure 1. $\beta$-CD-AITC sample $(0.14 \mathrm{~g})$ was inserted in a desorption cell (volume of the headspace of $44 \mathrm{~mL}$ ). A humidified helium stream was blown through the cell at a constant flow rate $(20 \mathrm{~mL} / \mathrm{min})$, high enough to avoid accumulation of the AITC molecules released in the inner space of the cell. The carrier gas was partially (for $a_{w}<1$ ) or fully humidified (for $a_{w}=1$ ) with the aid of a gas bubbler filled with deionized water conditioned at constant temperature in order to get the desired relative humidity. 
The gas mixture (AITC released and carrier gas) was injected in the inlet port of a gas chromatograph by means of an automatic injection valve previously programmed to execute a sampling sequence.

A Varian 3800 GC-FID (Les Ulis, France) equipped with a DB-5® column (Varian) (30 m x $0.2 \mathrm{~mm}$ i.d. $0.25 \mu \mathrm{m}$ ) and a flame ionization detector (FID; hydrogen, $30 \mathrm{~mL} / \mathrm{min}$; air, 300 $\mathrm{mL} / \mathrm{min}$; nitrogen, $30 \mathrm{~mL} / \mathrm{min}$ ) was used. Helium was used as carrier gas with a flow rate of $20 \mathrm{~mL} / \mathrm{min}$. The oven temperature was kept constant at $180^{\circ} \mathrm{C}$. Injector and detector temperatures were set at $250^{\circ} \mathrm{C}$.
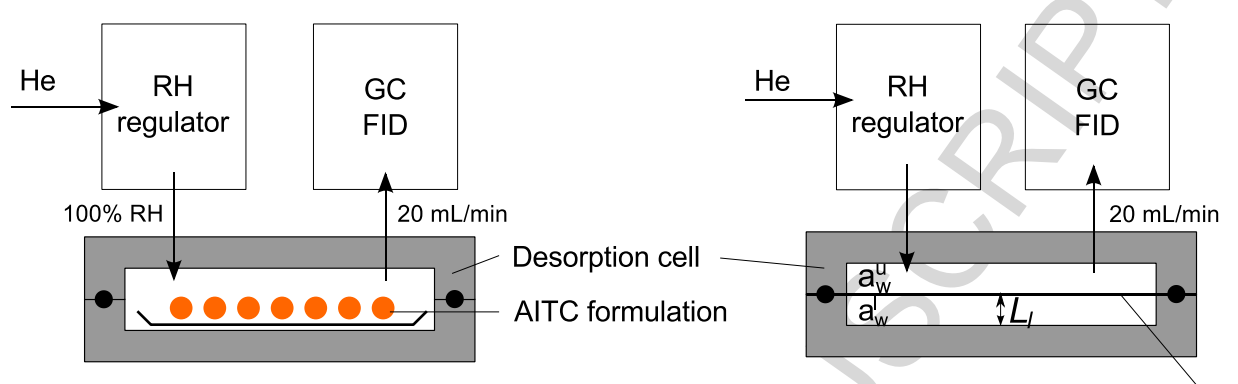

film, thickness $e_{f}$

Figure 1 - Scheme of the desorption cell.

Left: Scheme of the system used to measure AITC release. Orange dots present $\beta$-CD - AITC complexes. Right: scheme of the system used for experimental validation. The cell is divided in two parts with testing film (black line) (section 2.5).

During calibration, pure AITC (ranging from 1.2 to $8.4 \mathrm{mg}$ ) was placed in the cell on a glass support. The test was stopped when all AITC was evaporated. The concentration of AITC in the gas phase $c_{\text {AITC }}(\mathrm{mL} / \mathrm{mL})$ was obtained by computing the integral of the peak concentration $c_{\text {AITC }}^{\text {peak }}$ (peak $/ \mathrm{mL}$ ) measured by the gas chromatograph, multiplied by the gas flow $\varphi(20 \mathrm{~mL} / \mathrm{min})$ :

$$
c_{\text {AITC }}(t)=\varphi \int_{0}^{t} c_{A I T C}^{p e a k} d t
$$

The release kinetics was expressed as in Li et al. (2007):

$$
c_{\text {AITC }}(t)=c_{\text {AITC }}(0) \exp \left(-(k t)^{n}\right)
$$

where $c_{A I T C}(0)$ is the theoretical initial AITC quantity encapsulated in $\beta-C D, k$ is the release rate and $n$ the order of reaction, assumed to be 1 due to the fact that the system described in Figure 1 (left) was not considered diffusion-limited.

At the beginning of the experiment, the quantity of AITC released increased to a maximum value as the relative humidity increased from zero to the set value and then decreased until all AITC was released. The time at which AITC started to decrease was taken to be $t=0$. The fitting was done by minimising the root mean square error between experimental and 
predicted data using the Levenberg-Marquardt algorithm, with the built-in nlinfit function in Matlab (MathWorks, Natick, USA).

Five different relative humidities were considered, with at least two replicates for each: 60, 70, 80, 90 and $100 \%$ RH.

\subsection{Experimental validation}

The AITC release from PLA $+\beta$-CD-AITC film (from both sides) with $5 \%$ of $\beta$-CD-AITC (see section 2.3) was studied at two relative humidity values: 80 and 100\% in the same system described in section 2.4 (Figure 1). The film $(157.3 \pm 13.3 \mathrm{mg}$ ) was positioned inside the cell and divided the cell in two parts. The bottom side of the cell was closed and the upper side was under dynamic flow as described before. The surface area was $88.4 \cdot 10^{-4} \mathrm{~m}^{2}$, and the volume of the headspace was $24 \mathrm{~mL}$.

\subsection{Determination of diffusivities}

All experiments were conducted at $20 \pm 0.1^{\circ} \mathrm{C}$.

\subsubsection{Water diffusivity}

Water diffusivity in PLA+ $\beta$-CD-AITC films was measured using a dynamic vapour sorption balance (DVS, Surface Measurement Systems, London, UK), following the procedure described in Angellier-Coussy et al. (2011). Samples (15.09 $\pm 1.90 \mathrm{mg}$ ) were cut in small cubes and placed in desorption pan with a great attention in order that slices do not touch one each other. The procedure consists in recording the evolution of the film sample mass with time as a function of relative humidity of air. The experiment was reproduced numerically and the diffusivity was fitted to experimental data. This was done on an exhausted film (without AITC anymore) to avoid any experiment disturbance to AITC release.

\subsubsection{AITC diffusivity}

PLA films containing $\beta$-CD-AITC complexes were completely desorbed of AITC by putting the samples in a stream of $\mathrm{N}_{2}$ at controlled temperature and relative humidity for at least one week. Then, they were put at equilibrium with both an AITC solution and a saturated saline solution $\left(\mathrm{Mg}\left(\mathrm{NO}_{3}\right)_{2}\right.$ for $50 \% \mathrm{RH}$ or $\left(\mathrm{NH}_{4}\right)_{2} \mathrm{SO}_{4}$ for $\left.80 \% \mathrm{RH}\right)$ in a hermetically sealed jar for at least 8 days. This ensured that the film was saturated in AITC and that it was at a specific water activity.

The samples were then put in a dynamic gas sorption analyser (IGA 003, Hiden Isochema, Warrington, $\mathrm{UK}$ ) with a $\mathrm{N}_{2}$ flux at controlled $\mathrm{RH}$. The observed changes in sample mass were attributed to AITC desorption and the diffusivity was determined by fitting the experimental data with the theoretical relation given by Crank (1975). Two RH were considered: $50 \%$ and $80 \%$. 


\section{Theoretical background}

\subsection{Description of the system}

The aim was to reproduce experimental conditions described in section 2.5. The same $5 \% \beta$ CD-AITC in PLA film was used to split the desorption cell in half: the upper half was maintained at a constant relative humidity $(\mathrm{RH})$ with a controlled Helium flux, the lower half was considered to be initially at $50 \% \mathrm{RH}$, representative of the relative humidity of air.

Validation was made by comparing the experimental and simulated AITC content remaining in the film.

\subsubsection{Hypotheses}
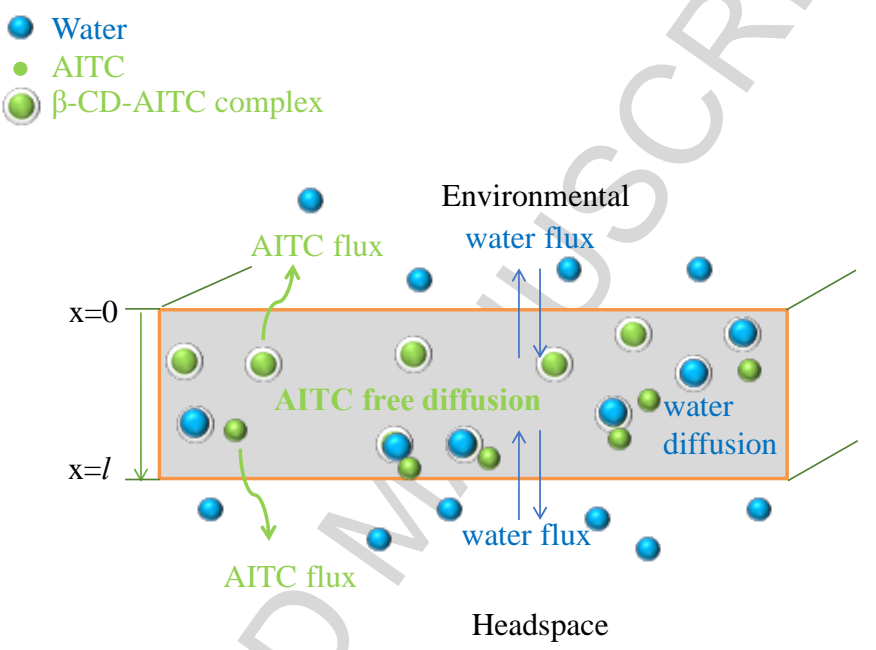

Figure 2 - Scheme describing the water dependent diffusion-reaction mechanism in the packaging material.

The water and AITC mass transfer through the polymeric matrix was calculated using Fick's laws considering a monodirectional transfer, perpendicular to the film surface (Figure 2).

Diffusion into $\beta$-CD complexes and of $\beta$-CD complexes was neglected.

The following parameters were considered constant and homogeneous in the system: relative humidity, temperature, AITC diffusivity, water diffusivity. Moreover, no variation of the headspace volume was considered.

AITC content in the film was split into two quantities: AITC that was encapsulated in $\beta$-CD, AITC $-e$, and AITC that was released and thus free to diffuse within the film, AITC $-f$. The first decreased in favour of the latter, following the pseudo first-order reaction described in section 2.4.

\subsection{Equations}

In the film, the following partial differential equations (PDE) system was considered: 


$$
\left\{\begin{array}{l}
\frac{\partial c_{w}}{\partial t}=D_{w} \nabla c_{w} \\
\frac{\partial c_{A I T C-e}}{\partial t}=-k c_{A I T C-e} \\
\frac{\partial c_{A I T C-f}}{\partial t}=D_{A I T C} \nabla c_{A I T C-f}+k c_{A I T C-e}
\end{array}\right.
$$

where $c_{w}, c_{A I T C-e}$ and $c_{A I T C-f}$ are the water, encapsulated AITC and free AITC concentrations in the film, respectively; $D_{w}$ and $D_{\text {AITC }}$ are the water and AITC diffusivities in PLA, respectively; and $k$ is the reaction rate constant described in section 2.4. Note that $k$ depends on the relative humidity of the film. This relationship constitutes the coupling between mass transfer and AITC release, and was modelled using the following equation:

$$
k=\alpha \exp \left(\beta a_{w}\right)
$$

where $\alpha$ and $\beta$ are fitting parameters and $a_{w}$ is the water activity of the film. Water activity and moisture content of the film are related by the Guggenheim, Anderson and de Boer (GAB) model (Blahovec and Yanniotis, 2007):

$$
c_{w}=\frac{X_{m} C K a_{w}}{\left(1-K a_{w}\right)\left(1-K a_{w}+C K a_{w}\right)}
$$

where $X_{m}, K$ and $C$ are the free sorption parameters and were fitted to an experimental sorption curve.

\subsubsection{Boundary conditions}

A flux boundary condition was applied at the upper and lower surface of the film (in $x=0$ and $\mathrm{x}=1$, Figure 2), following Fick's first law:

$$
\left\{\begin{array}{lll}
D_{w} \nabla c_{w} & = & j_{w} \\
D_{A I T C} \nabla c_{A I T C-f} & = & j_{A I T C-f}
\end{array}\right.
$$

The mass fluxes $j_{i}$ of constituents $i$ were computed as:

$$
j_{i}=-h_{m}\left(c_{i, \Gamma}-c_{i, e x t}\right)
$$

where $c_{i, \Gamma}$ is the concentration of constituent $i$ at the surface $\Gamma, c_{i, e x t}$ is the concentration of constituent $i$ exterior to the surface considered (either the headspace or the environment) and $h_{m}$ is the external mass transfer coefficient $\left(\mathrm{m} \cdot \mathrm{s}^{-1}\right)$, supposed to be the same for both sides of the film and calculated with a high Biot mass transfer number $\left(B i=10^{6}\right)$, characteristic of this diffusion-limited case:

$$
h_{m}=\frac{B i D_{A I T C}}{L_{c}}
$$

here, $L_{C}$ is a characteristic length taken as half the thickness of the packaging and $D_{\text {AITC }}$ the lowest value of diffusivity for AITC at $20^{\circ} \mathrm{C}$. 


\subsubsection{Initial conditions}

The film was considered to be dry at $t=0$, i.e. $a_{w}=0$ with only encapsulated AITC, i.e. $c_{A I T C-f}(t=0)=0$. The initial encapsulated AITC concentration depended on the formulation of the material (section 2.2):

$$
c_{A I T C-e}(t=0)=I E \frac{m_{A I T C}}{m_{f}}
$$

where $I E$ is the inclusion efficiency defined in Eq. 1, $m_{\text {AITC }}$ is the mass of AITC put in the formulation and $m_{f}$ the mass of the film used for the experiment.

\subsubsection{Headspace}

Water and AITC content in the headspace (lower half of the desorption cell, Figure 1) were computed with the mass balance due to the fluxes from the film:

$$
\begin{cases}\left.\frac{\partial c_{w}}{\partial t}\right|_{l} & =\frac{S_{f}}{V_{l}} j_{w} \\ \left.\frac{\partial c_{A I T C-f}}{\partial t}\right|_{l} & =\frac{S_{f}}{V_{l}} j_{A I T C-f}\end{cases}
$$

\subsection{Sensitivity analysis}

\subsubsection{Screening}

First, a systematic screening of the parameters was undertaken. Parameters were varied independently from each other following a one-factor-at-a-time method. The upper and lower bounds of each parameter were defined to be representative of their experimental uncertainties and for each simulation one parameter was varied while the others remained at a reference value. For each parameter $i$, the influence of parameter variation was computed as:

$$
I_{i}=100 \frac{y\left(x_{i}^{\max }\right)-y\left(x_{i}^{\text {min }}\right)}{y\left(x_{i}^{r e f}\right)}
$$

where $y$ is the output of the model considered (the total quantity of AITC in headspace or the remaining AITC quantity on the film), $x_{i}^{r e f}, x_{i}^{\min }$, and $x_{i}^{\max }$ are the reference, minimum and maximum values of parameter $i$.

This screening was used to sort out the parameters that were the less influential over the model output.

\subsubsection{Variance-based sensitivity analysis}

The parameters that were deemed the most influential over the model output $\left(I_{i}>20\right)$ were submitted to a variance-based sensitivity analysis, using Sobol's method (Sobol', 2001). 
Briefly stated, this method consists in generating a high number of simulations based on random drawings of the parameters, and to estimate the sensitivity of the parameters through variance. For each parameter, the first-order sensitivity index $S_{i}$ is computed as the ratio between the variance of the conditional expectation of parameter $x_{i}, V\left(E\left[y \mid x_{i}\right]\right)$, and total variance, $V(y)$ :

$$
S_{i}=\frac{V\left(E\left[y \mid x_{i}\right]\right)}{V(y)}
$$

Such principle can be generalised for higher order of sensitivity indices, in order to take into account possible interactions between parameters. For independent parameters, one can define the higher order sensitivity indices as follows:

$$
\begin{gathered}
S_{i j}=\frac{V\left(E\left[y \mid x_{i}, x_{j}\right]\right)}{V(y)}-S_{i}-S_{j} \\
S_{i j k}=\frac{V\left(E\left[y \mid x_{i}, x_{j}, x_{k}\right]\right)}{V(y)}-S_{i j}-S_{i k}-S_{j k}-S_{i}-S_{j}-S_{k}
\end{gathered}
$$

and so on. In practice, one often-used quantity is the total sensitivity index $S_{T_{i}}$ for parameter $i$, which is the sum of all indices relating to parameter $i$, and can be computed easily even for a high number of parameters (Homma and Saltelli, 1996). By comparing the total sensitivity index to the first-order sensitivity index of a given parameter, one can determine whether this parameter interacts with other parameters. If the two quantities remain close to each other, then the parameter considered does not interact with other parameters.

\subsection{Implementation}

The model was implemented in Matlab. The PDE system (Eqns. 4) was transformed into an ordinary differential equation system by discretizing the spatial terms with a second-order central difference method. The ODE system obtained was solved for each spatial node using the built-in ode15s Matlab routine. The mesh comprised 100 nodes.

The screening of parameters was performed in Matlab with a dedicated script, and the variance-based sensitivity analysis was performed using the GSAT Toolbox for Matlab developed by Cannavó (2012).

\section{$4 \quad$ Results and discussion}

\subsection{Input parameters values}

The pseudo first-order assumption of Eq. 3 proved to be sufficient, data fitting showing $R^{2}$ consistently higher than 0.91 for the determination of the release rate $k$ on experimental data at the different $a_{w}$ values. Parameters $\alpha$ and $\beta$ of Eq. 5 were fitted on these data and yielded 
the following results: $\alpha=1.09 \cdot 10^{-6} \mathrm{~s}^{-1}$ and $\beta=3.79$. The rate of release of AITC by $\beta$-CD was found to increase with increasing $a_{w}$ (Figure 3). Individual fits at various water activities are available in Supplementary Material 1.

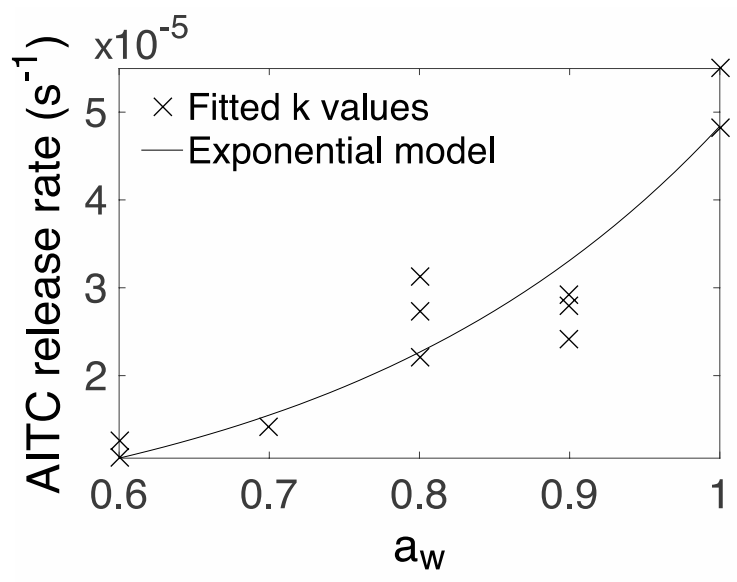

Figure 3 - Exponential model fitting for the release parameter $k$

The diffusivity of AITC in PLA increased with increasing $a_{w}$, with values of $3.8 \cdot 10^{-15}$ $\pm 6 \cdot 10^{-16} \mathrm{~m}^{2} \cdot \mathrm{s}^{-1}$ and $4.7 \cdot 10^{-15} \pm 7 \cdot 10^{-16} \mathrm{~m}^{2} \cdot \mathrm{s}^{-1}$ for $a_{w}=0.5$ and $a_{w}=0.8$, respectively.

Water diffusivity in PLA $+\beta$-CD-AITC film was assessed at a wide range of water activities: from 0.05 to 0.95 . The diffusivity decreased with increasing water activity. The average value was of $3.6 \cdot 10^{-12} \pm 2 \cdot 10^{-12} \mathrm{~m}^{2} \cdot \mathrm{s}^{-1}$. The high uncertainty $(56 \%)$ can be attributed in equal proportions to the variability between replicates, caused by variations in material processing (due to $\beta$-CD-AITC dispersion that impacted the water solubility in the film) and to the variation caused by the change in water activity. This uncertainty has to be tempered by the fact that the water diffusivity has no influence on the model (section 4.3.1).

\subsection{Validation of the model}

Water activity of the lower half of the desorption cell at $\mathrm{t}=0, a_{w}^{l}$, was assumed to be of 0.5 and the water activity of the upper half, $a_{w}^{u}$, was controlled by the relative humidity of the gas carrier flux.

Data were acquired at two $a_{w}^{u}$ values: 0.8 and 1.0. Simulations were conducted accordingly to these values, for comparison purposes (Figure). The error bars shown in Figure 4 were estimated as the average of the combination of the experimental error on the measure and the standard deviation between replicates. 


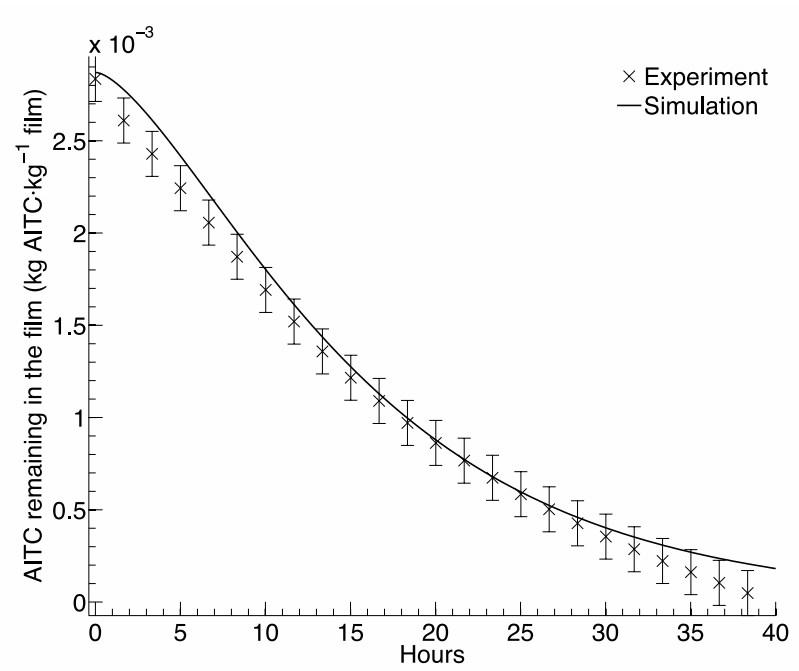

(a)

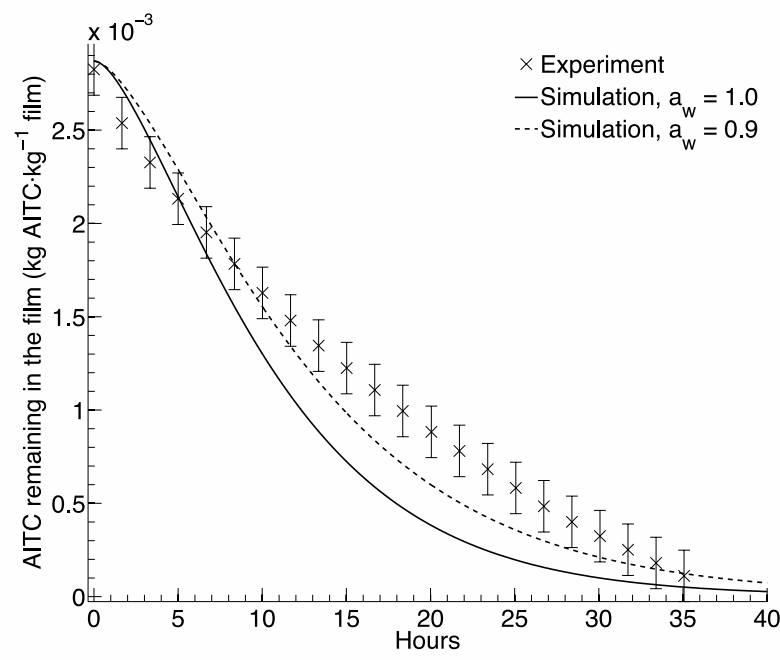

(b)

Figure 4 - Total AITC content remaining in the film (a) at $a_{w}^{u}=0.8$ and (b) at $a_{w}^{u}=1.0$.

Results showed better agreement between simulation and experience at $a_{w}^{u}=0.8$ (Figure a) than at $a_{w}^{u}=1.0$ (Figure b) where the loss of AITC was quicker for the simulation than for the experiment. This discrepancy can be attributed to a possible uncertainty on the estimation of the reactional constants (section 4.1) that are highly sensitive parameters (see section 4.3) and to their water content-dependency. Moreover, it is possible that the set point $a_{w}^{u}$ of 1.0 was not reached experimentally since so high $a_{w}$ is difficult to reach. The RMSE of the simulation for $a_{w}^{u}=0.8,9.95 \cdot 10^{-5} \mathrm{~kg}^{\cdot} \mathrm{kg}^{-1}$, was less than the average experimental error, $1.22 \cdot 10^{-4} \mathrm{~kg} \cdot \mathrm{kg}^{-1}$, whereas for the simulation at $a_{w}^{u}=1.0$, the RMSE was of $3.36 \cdot 10^{-4}$ $\mathrm{kg} \cdot \mathrm{kg}^{-1}$ for an average experimental error of $1.38 \cdot 10^{-4} \mathrm{~kg}^{\cdot} \mathrm{kg}^{-1}$. The set point $a_{w}^{u}$ of 1.0 was probably not reached experimentally as mentioned before and evident from Figure 4b: one can consider that the actual $a_{w}^{u}$ was closer to 0.9 (Figure b). Considering simulation at $a_{w}^{u}$ equal to 0.9 , the RMSE was closer to the experimental error: $1.85 \cdot 10^{-4} \mathrm{~kg} \cdot \mathrm{kg}^{-1}$. 
In spite of the high complexity of the system investigated with AITC and moisture coupled diffusion and release, the model described well the active agent release pattern. Note that none of the parameters were re-adjusted nor fitted on the experimental release data obtained on films and were all determined using independent experiments. Discrepancy between experimental and predicted results, especially at high $a_{w}$, is inherent to the complexity of the system and experimental variability. To deepen the analysis of the results and better identify the sources of variability in the system, next part of this work was dedicated to sensitivity analysis.

\subsection{Sensitivity analysis}

\subsubsection{Screening of parameters}

In order to sort out the parameters that were the most obviously influential, a screening study was conducted. The min and max values taken by the parameters are indicated in Table 1. Note that variations indicated in Table 1 are not only due to sensitivity of measuring devices but included also unwanted variations due the difficulty to master some of the parameters (e.g. $\left.a_{w}^{l}(t=0)\right)$ that were therefore considered varying in their worst case to maximize their impact if any.

Table 1 - Parameters values for sensitivity analyses

\begin{tabular}{|c|c|c|c|c|}
\hline Parameter & $\begin{array}{l}\text { Reference } \\
\text { value }\end{array}$ & Min value & Max value & Source \\
\hline$D_{w}\left(\mathrm{~m}^{2} \cdot \mathrm{s}^{-1}\right)$ & $5.96 \cdot 10^{-12}$ & $3.90 \cdot 10^{-12}$ & $8.03 \cdot 10^{-12}$ & $\begin{array}{l}\text { Variation from the type of PLA (Siparsky et } \\
\text { al., 1997) }\end{array}$ \\
\hline$D_{A I T C}\left(\mathrm{~m}^{2} \cdot \mathrm{s}^{-1}\right)$ & $4.22 \cdot 10^{-15}$ & $3.42 \cdot 10^{-15}$ & $5.01 \cdot 10^{-15}$ & Experimental uncertainty (this work). \\
\hline$\alpha\left(\mathrm{s}^{-1}\right)$ & $1.72 \cdot 10^{-6}$ & $1.10 \cdot 10^{-6}$ & $2.25 \cdot 10^{-6}$ & Estimation uncertainty (this work). \\
\hline$\beta$ & 3.23 & 2.87 & 3.59 & Estimation uncertainty (this work). \\
\hline$X_{m}$ & $6.5 \cdot 10^{-3}$ & $5.6 \cdot 10^{-3}$ & $7.4 \cdot 10^{-3}$ & Estimation uncertainty (this work). \\
\hline$K$ & 0.592 & 0.546 & 0.645 & Estimation uncertainty (this work). \\
\hline$C_{g}$ & 7.014 & 5.234 & 8.794 & Estimation uncertainty (this work). \\
\hline$a_{w}^{u}$ & 0.8 & 0.6 & 1.0 & Experimental variation. \\
\hline$a_{w}^{l}(t=0)$ & 0.5 & 0.4 & 0.6 & Plausible variation for air. \\
\hline $\begin{array}{c}c_{A I T C-e}(t=0) \\
\left(\mathrm{kg} \cdot \mathrm{kg}^{-1}\right)\end{array}$ & $2.87 \cdot 10^{-3}$ & $2.18 \cdot 10^{-3}$ & $3.48 \cdot 10^{-3}$ & $\begin{array}{l}\text { Plausible variation of the inclusion } \\
\text { coefficient. }\end{array}$ \\
\hline$e_{f}(\mu \mathrm{m})$ & 30 & 26 & 34 & Experimental uncertainty on the measure. \\
\hline$L_{l}=\frac{V_{l}}{S_{f}}(\mathrm{~mm})$ & 5.0 & 4.0 & 6.0 & Plausible variation. \\
\hline
\end{tabular}


The screening allowed to rule out the following parameters: GAB equation parameters and $D_{w}$ (Figure ). Moreover, geometrical parameters $L_{l}$ and $e_{f}$ were also ruled out are since they are well-mastered parameters.

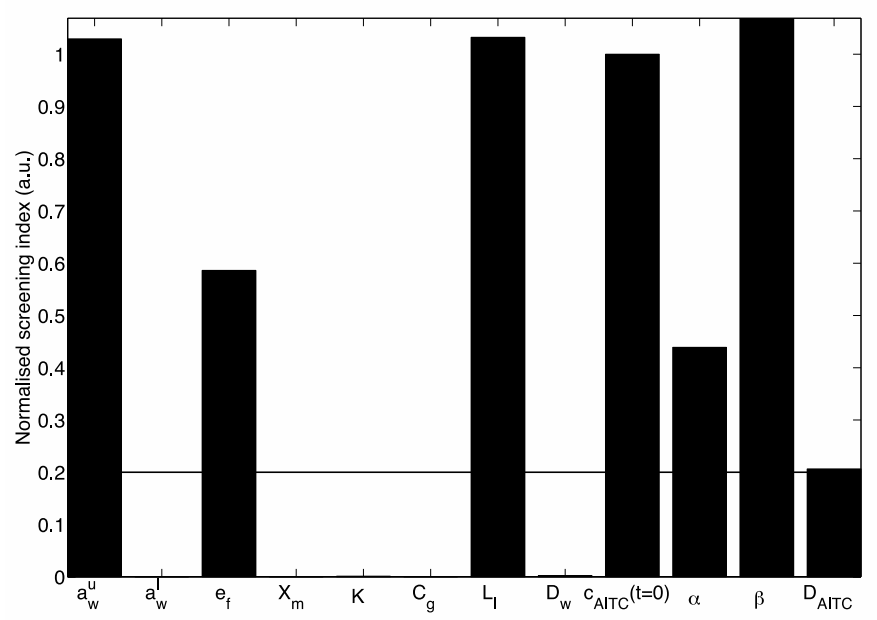

Figure 5 - Screening results.

The horizontal bar indicates the threshold beyond which a parameter was deemed influential (0.2).

\subsubsection{Variance-based sensitivity analysis}

Following the first screening, the remaining parameters $\left(D_{A I T C}, c_{A I T C-e}(t=0), \alpha, \beta, a_{w}^{l}\right)$ were then submitted to a global sensitivity analysis, following Sobol's method (Figure ). Except for $a_{w}^{u}$, the parameters took the same values previously indicated in Table 1 . The $a_{w}^{u}$ range was set to $0.75-0.85$, centred on the experimental value of 0.8 previously used for validation (whereas in the screening it was swept to cover the different possible experimental set-ups). Another range was considered (0.90-1.0) to cover the higher water activity. The results were very similar to the study centred on $a_{w}^{u}=0.8$, and are available in Supplementary Material 2. This sensitivity analysis showed that:

1. AITC diffusivity plays no influence on the ability of the system to release AITC in the headspace;

2. The release kinetics are the most important parameters, besides the obvious initial AITC content.

3. There is no interaction between parameters: first-order indices are of the same order of magnitude as total indices. 


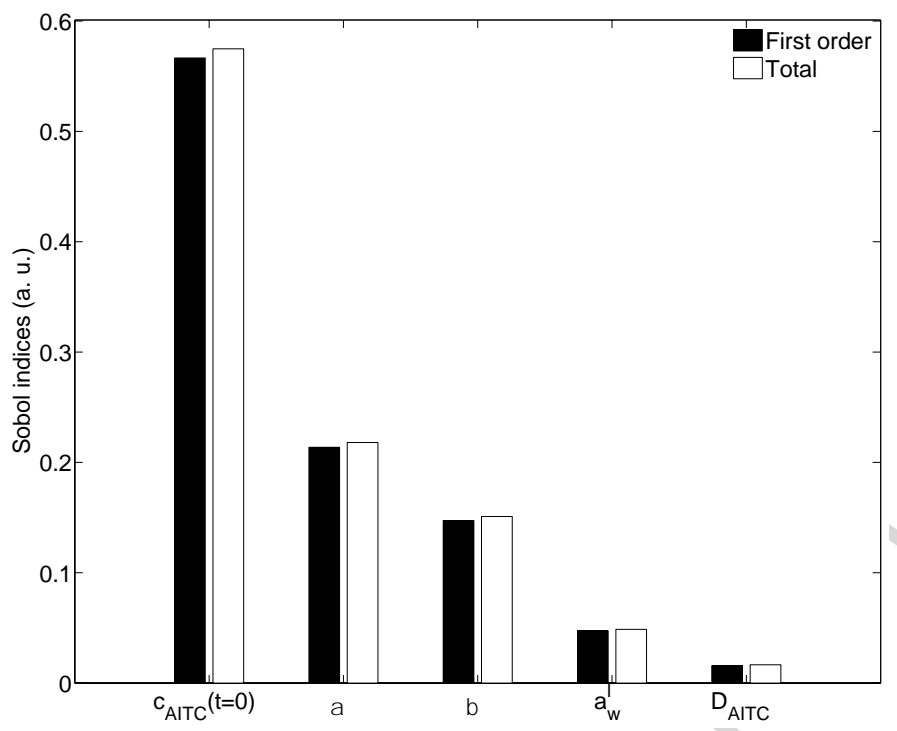

Figure 6 - Global sensitivity analysis results for $a_{w}^{l}$ between 0.75 and 0.85 .

\subsection{Application}

The model was used to investigate an application case that consisted of a package composed of high-barrier tray containing a fictive foodstuff closed by a permeable lid film, acting as antimicrobial agent. The lid film was PLA with homogenously dispersed molecules of AITC encapsulated into $\beta-C D$ at variable concentrations. The growth of a microbial population in the fictive foodstuff, for which the AITC content was considered to be at equilibrium with the headspace, was taken into account. Compared to the validation case (section 2.5), the headspace in this study was considerably larger: $3.6 \cdot 10^{-4} \mathrm{~m}^{3}$ (compared to $4.42 \cdot 10^{-5} \mathrm{~m}^{3}$ previously).

Simulations were conducted at an initial headspace $a_{w}$ value of 0.8 . Exterior $a_{w}$ was assumed to be of 0.5 (e.g. conventional storage conditions). $1 \%$ and $5 \%$ PLA+ $\beta$-CD-AITC films were considered. As a reference, a simulation was also conducted with $0 \% \beta$-CD-AITC concentration.

The growth rate of bacteria $\mu$ was assumed to depend on AITC content with the following relation:

$$
\begin{aligned}
& \mu=\mu_{\max }\left(1-\frac{\left.c_{A I T C-f}\right|_{H S}}{M I C}\right),\left.c_{A I T C-f}\right|_{H S}<M I C \\
& \mu=0,\left.c_{A I T C-f}\right|_{H S} \geq M I C
\end{aligned}
$$

where $\mu_{\max }$ is the maximal growth rate for a given bacteria at $20^{\circ} \mathrm{C}$ and $M I C$ the minimum inhibitory concentration of AITC, representing the concentration of AITC beyond which there is no microbial growth for a given microorganism. 
This growth rate was then used to assess the microbial population $N$ in the fictive foodstuff with the classical model from Rosso et al. (1995):

$$
\frac{\partial N}{\partial t}=\mu N\left(1-\frac{N}{N_{\max }}\right)
$$

where $N_{\max }$ is the maximum population.

Three bacteria often found in food systems such as club sandwiches were considered: Escherichia coli, Staphylococcus aureus and Salmonella enteridis. Parameters for each case are summarised in Table 2.

Table 2 - Microbiological parameters and simulation results

$$
\begin{array}{lll}
\text { E. coli } & \text { S. aureus } & \text { S. enteridis }
\end{array}
$$

\begin{tabular}{|c|c|c|c|c|}
\hline \multicolumn{2}{|c|}{$\operatorname{MIC}\left(10^{-5} \mathrm{~kg} \cdot \mathrm{m}^{-3}\right)^{(1)}$} & 3.4 & 11.0 & 11.0 \\
\hline \multicolumn{2}{|l|}{$\mu_{\max }\left(\mathrm{h}^{-1}\right)$} & $0.186^{(2)}$ & $0.439^{(3)}$ & $0.320^{(4)}$ \\
\hline \multicolumn{2}{|c|}{$N(t=0)\left(\log \mathrm{CFU} \cdot \mathrm{g}^{-1}\right)$} & 3.00 & 3.00 & 3.00 \\
\hline \multicolumn{2}{|c|}{$N_{\max }\left(\log \mathrm{CFU} \cdot \mathrm{g}^{-1}\right)$} & 9.00 & 9.00 & 9.00 \\
\hline \multirow{2}{*}{$\begin{array}{l}\text { Time to reach } \\
\text { MIC (h) }\end{array}$} & $1 \% \beta$-CD-AITC & & 28 & 28 \\
\hline & $5 \% \beta$-CD-AITC & 2.7 & 6.8 & 6.8 \\
\hline \multirow{2}{*}{$\begin{array}{l}N(t=40 h) \\
\left(\log \text { CFU } \cdot g^{-1}\right)\end{array}$} & $1 \% \beta$-CD-AITC & 3.44 & 5.71 & 4.97 \\
\hline & $5 \%$ & 3.14 & 3.76 & 3.55 \\
\hline
\end{tabular}

(1) Data from Isshiki et al., 1992. (2) Data from Sutherland et al., $1995, \mathrm{~T}=20^{\circ} \mathrm{C}, \mathrm{pH}=5.28$.

(3) Mean value from Medveov and Valk, 2012, $\mathrm{T}=21^{\circ} \mathrm{C}$. (4) Data from Singh et al., 2011, $\mathrm{T}=20^{\circ} \mathrm{C}$.

The simulations demonstrate the ability of the PLA+ $\beta$-CD-AITC system to reduce the growth of the chosen bacteria in a food package (Figure ). For Staphylococcus aureus (Figure 7c), that was the most resistant bacteria (highest MIC, highest $\mu_{\max }$ ), the MIC was reached in $6.8 \mathrm{~h}$ (Figure d) and the growth limited to $3.76 \log \mathrm{CFU} \cdot \mathrm{g}^{-1}$ at $5 \% \beta$-CD-AITC and 5.71 $\log \mathrm{CFU} \cdot \mathrm{g}^{-1}$ at $1 \% \beta$-CD-AITC (Table 2 ). As expected, these results also indicate that 5\% $\beta$ CD-AITC is more efficient than 1\%. However, both formulations permit to achieve a significant log reduction for the three bacterial populations investigated compare to the growth without antimicrobials (Figure 7): ranging between 1.5 for the $1 \% \beta$-CD-AITC complex to 2.3 for the most efficient $5 \% \beta$-CD-AITC complex (in the case of $S$. aureus). Supposing that the total mesophilic aerobic flora behaves as the three aforementioned bacteria, considering a $\mathrm{N}(\mathrm{t}=0)$ of $3 \log$ CFU.g-1 which is a typical initial value, the final population will be below the usual criterion for microbial quality limit in foodstuff of $10^{7}$ $\mathrm{CFU} \cdot \mathrm{g}^{-1}$ (Lee, 2010) for the both active formulations. 
It should be noted that these results would need a proper confrontation to experimental data to confirm this quantitative analysis. However, sufficient care was taken to choose from the literature the microbiological model parameters closest to the situation reproduced numerically here. Nevertheless, these data allow a preliminary evaluation of the expected effect of a PLA-film incorporated with AITC on microbial growth in a packaged food.
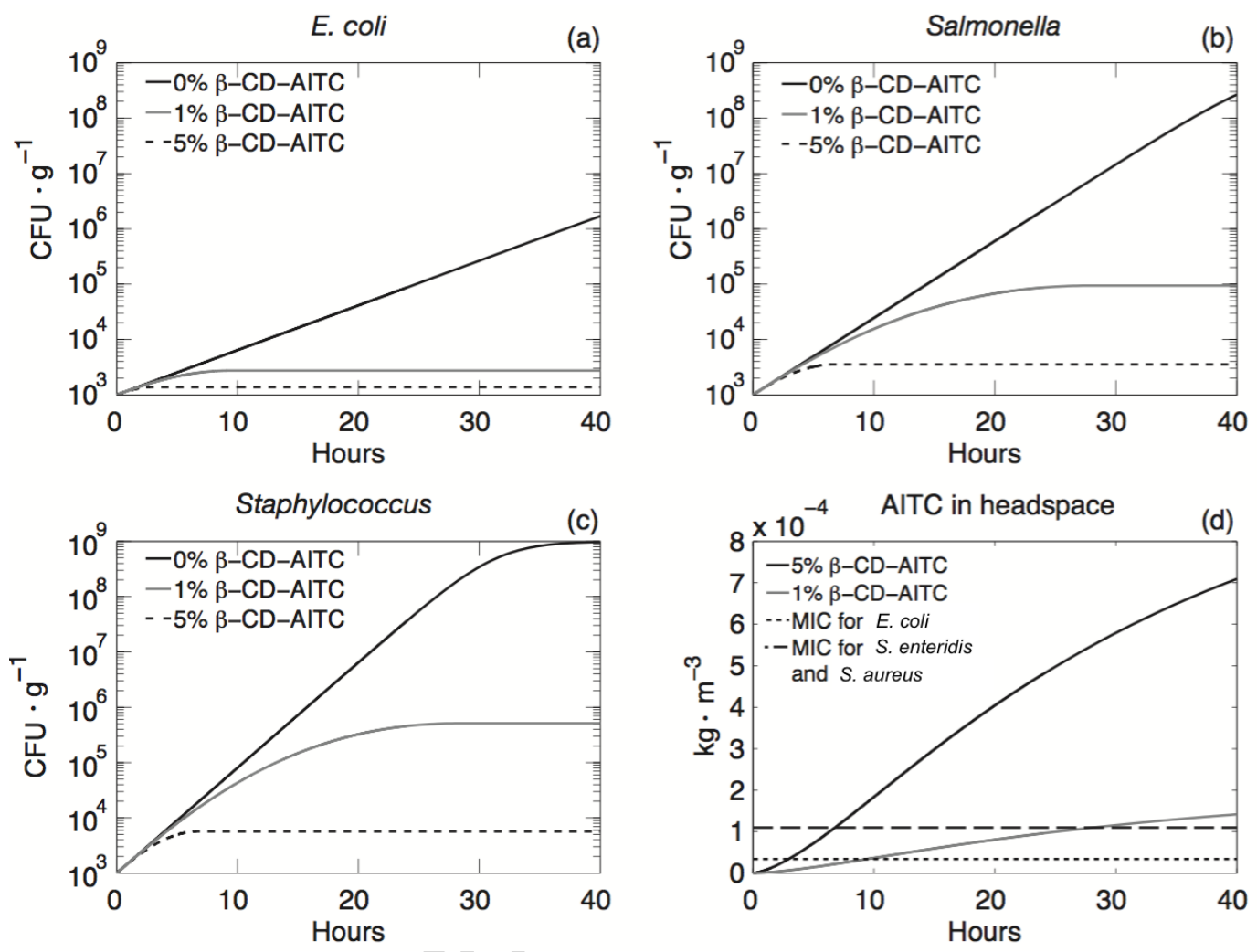

Figure 7 - Variation of microbial growth with AITC content (a, b, c) and AITC content in the headspace (d).

\section{Conclusion}

For active food packaging the problem of providing tailored release and a sufficient quantity of the active agent in the food through the packaging headspace is very complex. In this paper, a model for the release of an antimicrobial agent (AITC) was developed. The proposed approach was validated experimentally at two relative humidity values: 80 and $100 \%$ RH, representative of the levels encountered within food packages of perishable moist foods. The model proved to be sufficiently accurate in a quantitative manner.

A sensitivity study was conducted with help of the model and demonstrated that the masstransfer related parameters (diffusivity, mass transfer coefficient) were of limited influence over the ability of the active film to release antimicrobial agent. This work clearly demonstrated that the most influential parameters were the initial antimicrobial content and the kinetics parameters that govern the release of the antimicrobial agent from the $\beta-C D$ complexes. 
The model was then used to simulate a practical case study, by investigating the influence of the active packaging on the growth of Escherichia coli, Salmonella enteridis and Staphylococcus aureus in the fictive foodstuff. At the relative humidity considered $(80 \% \mathrm{RH})$, the model allowed to give an estimation of the reduction of the microbial growth. It should be emphasized that the microbial model implemented remained simple, and that the accuracy could be enhanced by taking into account other microbiological phenomena. However, it was enough to demonstrate the efficiency of such active packaging, even at low antimicrobial agent amounts.

All experiments and simulations were performed at $20^{\circ} \mathrm{C}$. To be able to consider impact of refrigeration condition and temperature abuse, lower temperatures should be investigated as a perspective of the present study.

\section{Acknowledgements}

This work was funded by the French Agence Nationale de la Recherche within the framework of European NextGenPack project.

The work of prof. Elena Torrieri was supported by a Campania Region fund (grant number/CUP: B25B09000080007) within the program "POR CAMPANIA FSE 2007/2013" - project CARINA (Safety sustainability and competitiveness of the agro-food production in Campania).

\section{$7 \quad$ References}

Angellier-Coussy, H., Gastaldi, E., Gontard, N., \& Guillard, V. (2011). Influence of processing temperature on the water vapour transport properties of wheat gluten based agromaterials. Industrial Crops and Products, 33(2), 457-461.

Angellier-coussy, H., Guillard, V., Guillaume, C., \& Gontard, N. (2013). Role of packaging in the smorgasbord of action for sustainable food consumption. Agro Food Industries, 23(4), 15-19.

Blahovec, J., \& Yanniotis, S. (2007). GAB Generalized Equation for Sorption Phenomena. Food and Bioprocess Technology, 1(1), 82-90.

Cagnon, T., Méry, A., Chalier, P., Guillaume, C., \& Gontard, N. (2013). Fresh food packaging design: A requirement driven approach applied to strawberries and agrobased materials. Innovative Food Science \& Emerging Technologies, 20, 288-298.

Cannavó, F. (2012). Sensitivity analysis for volcanic source modeling quality assessment and model selection. Computers \& Geosciences, 44, 52-59.

Cerisuelo, J. P., Bermúdez, J. M., Aucejo, S., Catalá, R., Gavara, R., \& HernándezMuñoz, P. (2013). Describing and modeling the release of an antimicrobial agent from an active PP/EVOH/PP package for salmon. Journal of Food Engineering, $116(2), 352-361$.

Cerisuelo, J. P., Muriel-Galet, V., Bermúdez, J. M., Aucejo, S., Catalá, R., Gavara, R., \& Hernández-Muñoz, P. (2012). Mathematical model to describe the release of an antimicrobial agent from an active package constituted by carvacrol in a hydrophilic EVOH coating on a PP film. Journal of Food Engineering, 110(1), 26-37.

Chaix, E., Broyart, B., Couvert, O., Guillaume, C., Gontard, N., \& Guillard, V. (2015). Mechanistic model coupling gas exchange dynamics and Listeria monocytogenes 
growth in modi fi ed atmosphere packaging of non respiring food. Food Microbiology, 51, 192-205.

Crank, J. (1975). Diffusion in a Plane Sheet. In The Mathematics of Diffusion (2nd ed.). Oxford: Clarendon Press - Oxford.

Delaquis, P. J., \& Sholberg, P. L. (1997). Antimicrobial Activity of Gaseous Allyl Isothiocyanate. Journal of Food Protection, 60(8), 943-947.

Del Valle, E. M. M. (2004). Cyclodextrins and their uses: a review. Process Biochemistry, 39(9), 1033-1046.

Fang, C., Bandaru, N. M., Ellis, A. V., \& Voelcker, N. H. (2013). Beta-cyclodextrin decorated nanostructured SERS substrates facilitate selective detection of endocrine disruptorchemicals. Biosensors and Bioelectronics, 42, 632-639.

Guillard, V., Issoupov, V., Redl, A., \& Gontard, N. (2009). Food preservative content reduction by controlling sorbic acid release from a superficial coating. Innovative Food Science \& Emerging Technologies, 10(1), 108-115.

Homma, T., \& Saltelli, A. (1996). Importance measures in global sensitivity analysis of nonlinear models. Reliability Engineering \& System Safety, 52(1), 1-17.

Huang, X., Ye, H., \& Yam, K. L. (2013). Release mathematical model of active agent from packaging material into food. Mathematical Problems in Engineering, 2013. http://doi.org/10.1155/2013/607546

Isshiki, K., Tokuoka, K., Mori, R., \& Chiba, S. (1992). Preliminary Examination of Allyl Isothiocyanate Vapor for Food Preservation. Bioscience, Biotechnology, and Biochemistry, 56(9), 1476-1477.

Joo, M. J., Merkel, C., Auras, R., \& Almenar, E. (2012). Development and characterization of antimicrobial poly(l-lactic acid) containing trans-2-hexenal trapped in cyclodextrins. International Journal of Food Microbiology, 153(3), 297305.

Lagaron, J. M., Fernandez-Saiz, P., \& Ocio, M. J. (2007). Using ATR-FTIR spectroscopy to design active antimicrobial food packaging structures based on high molecular weight chitosan polysaccharide. Journal of Agricultural and Food Chemistry, 55(7), 2554-62.

Lee, D. . (2010). Packaging and the Microbial Shelf Life of Food. In Gordon L. Robertson (Ed.), Food Packaging and Shelf Life (pp. 55-79). CRC Press.

Li, X., Jin, Z., \& Wang, J. (2007). Complexation of allyl isothiocyanate by $\alpha$ - and $\beta$ cyclodextrin and its controlled release characteristics. Food Chemistry, 103(2), 461466.

Mahajan, P. V, Oliveira, F. A. R., Montanez, J. C., \& Frias, J. (2007). Development of user-friendly software for design of modified atmosphere packaging for fresh and fresh-cut produce. Innovative Food Science \& Emerging Technologies, 8(1), 84-92.

Mascheroni, E., Chalier, P., Gontard, N., \& Gastaldi, E. (2010). Designing of a wheat gluten/montmorillonite based system as carvacrol carrier: Rheological and structural properties. Food Hydrocolloids, 24(4), 406-413.

Mascheroni, E., Guillard, V., Gastaldi, E., Gontard, N., \& Chalier, P. (2011). Antimicrobial effectiveness of relative humidity-controlled carvacrol release from wheat gluten/montmorillonite coated papers. Food Control, 22(10), 1582-1591.

Mascheroni, E., Guillard, V., Nalin, F., Mora, L., \& Piergiovanni, L. (2010). Diffusivity of propolis compounds in Polylactic acid polymer for the development of antimicrobial packaging films. Journal of Food Engineering, 98(3), 294-301.

Medveov, A., \& Valk, L. (2012). Staphylococcus aureus: Characterisation and Quantitative Growth Description in Milk and Artisanal Raw Milk Cheese Production. In A. E. Ayman (Ed.), Structure and Function of Food Engineering. InTech

Ohta, Y., Takatani, K., \& Kawakishi, S. (2000). Kinetic and thermodynamic analyses of the cyclodextrin-allyl isothiocyanate inclusion complex in an aqueous solution.

Bioscience Biotechnology and Biochemistry, 64(1), 190-193.

Ohta, Y., Takatani, K., \& Kawakishi, S. (2004). Effects of Ionized Cyclodextrin on 
Decomposition of Allyl Isothiocyanate in Alkaline Solutions. Bioscience, Biotechnology, and Biochemistry, 68(2), 433-435.

Ozdemir, M., \& Floros, J. D. (2004). Active food packaging technologies. Critical Reviews in Food Science and Nutrition, 44(3), 185-193.

Plackett, D., Ghanbari-Siahkali, A., \& Szente, L. (2007). Behavior of $\alpha$ - and $\beta$ cyclodextrin-encapsulated allyl isothiocyanate as slow-release additives in polylactide-co-polycaprolactone films. Journal of Applied Polymer Science, 105(5), 2850-2857. http://doi.org/10.1002/app.26344

Plackett, D. V., Holm, V. K., Johansen, P., Ndoni, S., Nielsen, P. V., Sipilainen-Malm, T., ... Verstichel, S. (2006). Characterization of 1-polylactide and 1-polylactidepolycaprolactone co-polymer films for use in cheese-packaging applications. Packaging Technology and Science, 19(1), 1-24.

Ponce Cevallos, P. A., Buera, M. P., \& Elizalde, B. E. (2010). Encapsulation of cinnamon and thyme essential oils components (cinnamaldehyde and thymol) in $\beta$ cyclodextrin: Effect of interactions with water on complex stability. Journal of Food Engineering, 99(1), 70-75.

Raouche, S., Mauricio-Iglesias, M., Peyron, S., Guillard, V., \& Gontard, N. (2011). Combined effect of high pressure treatment and anti-microbial bio-sourced materials on microorganisms' growth in model food during storage. Innovative Food Science \& Emerging Technologies, 12(4), 426-434.

Reineccius, T. A., Reineccius, G. A., \& Peppard, T. L. (2003). Flavor Release from Cyclodextrin Complexes: Comparison of Alpha, Beta, and Gamma Types. Journal of Food Science, 68(4), 1234-1239.

Rosso, L., Lobry, J. R., Bajard, S., \& Flandrois, J. P. (1995). Convenient Model To Describe the Combined Effects of Temperature and $\mathrm{pH}$ on Microbial Growth. Applied and Environmental Microbiology, 61(2), 610-6.

Simpson, R., \& Carevic, E. (2004). Designing a modified atmosphere packaging system for foodservice portions on nonrespiring foods: optimal gas mixture and food/headspace ratio. Foodservice Research International, 14, 257-272.

Singh, A., Korasapati, N. R., Juneja, V. K., Subbiah, J., Froning, G., \& Thippareddi, H. (2011). Dynamic Predictive Model for the Growth of Salmonella spp. in Liquid Whole Egg. Journal of Food Science, 76(3), M225-M232.

Siparsky, G. L., Voorhees, K. J., Dorgan, J. R., \& Schilling, K. (1997). Water Transport in Polylactic Acid (PLA), PLA / Polycaprolactone Copolymers, and PLA / Polyethylene Glycol Blends, 5(3).

Sobol', I. M. (2001). Global sensitivity indices for nonlinear mathematical models and their Monte Carlo estimates. Mathematics and Computers in Simulation, 55(1-3), 271-280.

Sutherland, J. P., Bayliss, A. J., \& Braxton, D. S. (1995). Predictive modelling of growth of Escherichia coli O157:H7: the effects of temperature, $\mathrm{pH}$ and sodium chloride. International Journal of Food Microbiology, 25(1), 29-49.

Xanthopoulos, G., Koronaki, E. D., \& Boudouvis, A. G. (2012). Mass transport analysis in perforation-mediated modified atmosphere packaging of strawberries. Journal of Food Engineering, 111(2), 326-335. 

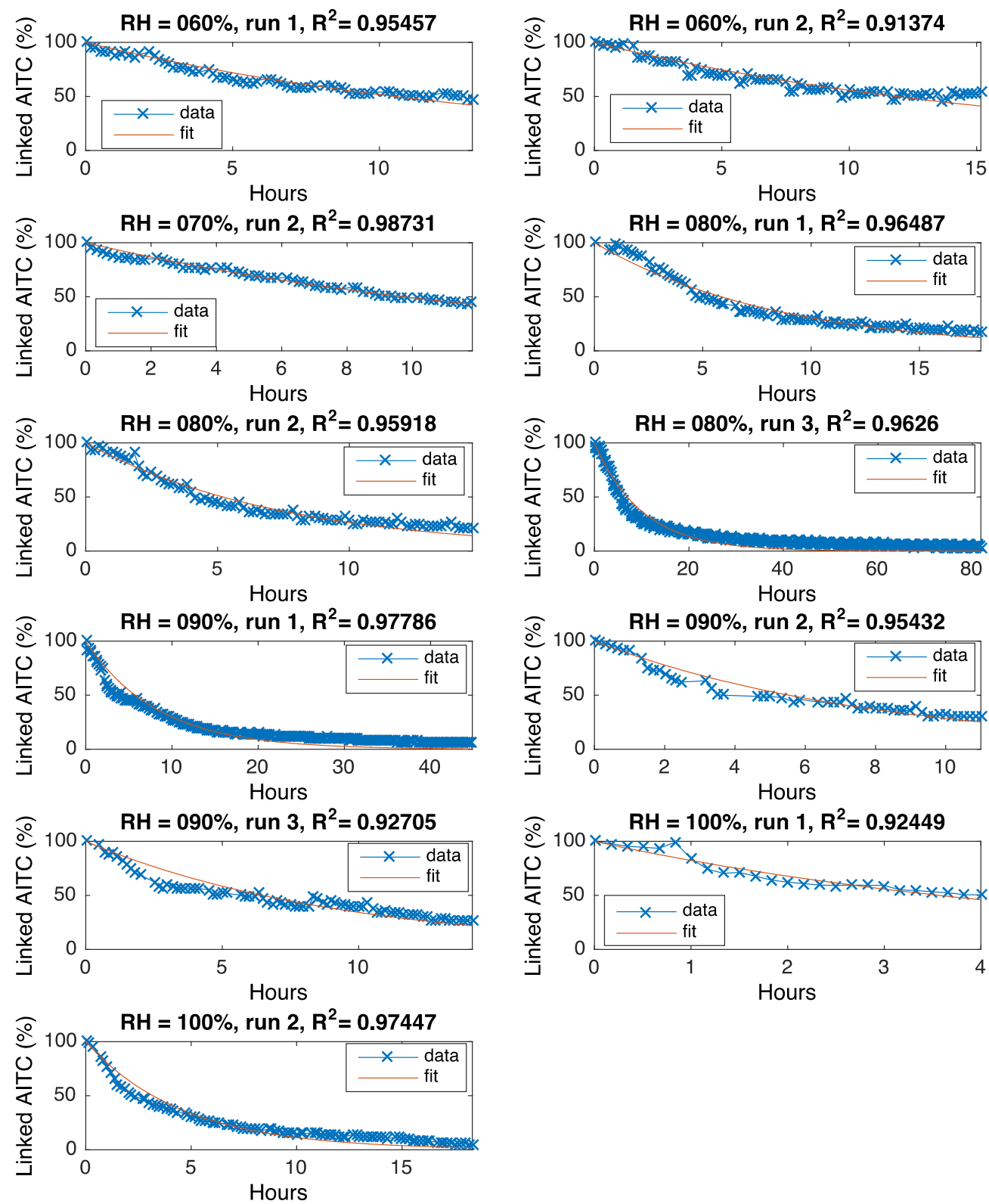

Supplementary Material 1 - Fit of the AITC release from B-CD complexes at water activities ranging from 0.6 to 1.0 . 


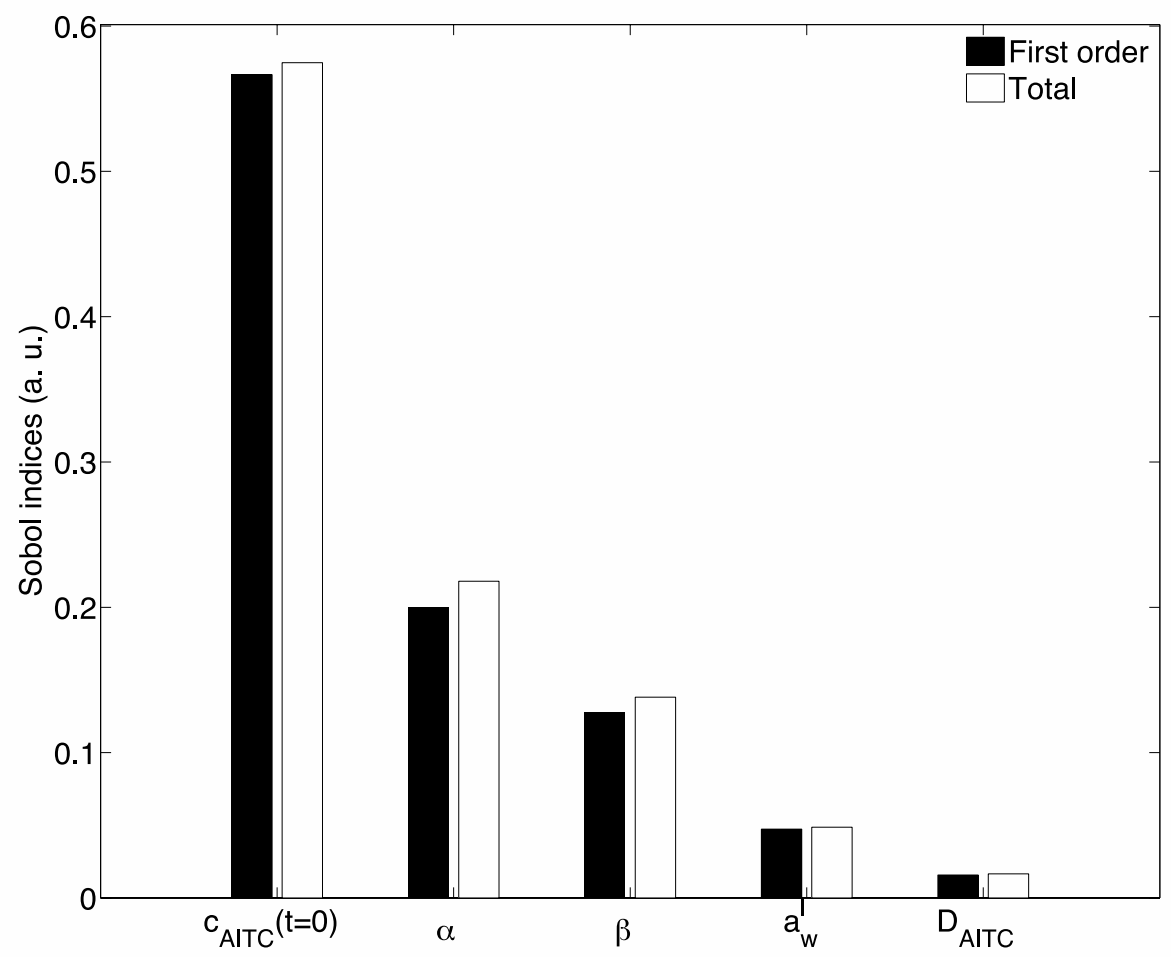

Supplementary Material 2 - Variance-based sensitivity analysis for aw ranging from 0.9 to 1.0 . 
Industrial relevance of the manuscript entitled "A mathematical model for tailoring antimicrobial packaging material containing encapsulated volatile compounds" submitted for publication in Innovative Food Science and Emerging Technologies.

This work is relevant to industrial considerations as it provides a framework for decision support systems to help manufacturers and researchers alike to tailor their active packaging. Indeed, the development of anti-microbial applications for food packaging is a time-consuming task, that, if undertaken from a sole experimental point of view, can also be expensive. The use of the simulation framework proposed (that was experimentally validated) helps investigate and compare multiple packaging configurations. Numerical simulation are made by changing the kinetics of release parameters and initial anti-microbial content within the packaging without requiring further experiments, the main issue lying on having plausible values for the parameters. 


\section{Highlights}

* A diffusion-reaction model to describe AITC release from inclusion complexes is proposed.

* The inputs were characterised experimentally and the model is experimentally validated.

* A sensitivity study showed the release kinetics were the most influential parameters

* The sensitivity study allowed to rule out the diffusivities.

* The model was applied to practical cases with food containing E. coli, S. aureus and $S$. enteridis. 